\title{
Retinal vasoproliferative tumor
}

\section{Tumor vasoproliferativo da retina}

Eduardo Ferrari Marback ${ }^{1,2}$, Ricardo Leitão Guerra ${ }^{2}$, Otacilio de Oliveira Maia Junior ${ }^{2}$, Roberto Lorens Marback ${ }^{1,2}$

\begin{abstract}
Retinal vasoproliferative tumor is a rare disease that has capillary hemangioma as the most frequent diferential diagnosis. The tumor is considered to be of reactive nature. It can be idiophatic or secondary to other ocular diseases such as: uveitis, retinitis pigmentosa, sickle cell disease, previous surgery and retinopathy of prematurity. Lesions with no exsudation or visual decrease can be observed. Lesions that need treatment can be managed by on or more modalities such as cryotherapy, a variety of lasers, surgical excision, radiation, and antiangiogenic intravitreal injections.
\end{abstract}

Keywords: Retina/pathology; Retinal neoplasms/diagnosis; Retinal neoplasms/ pathology; Retinal neoplasms/therapy

\section{RESUMO}

O tumor vasoproliferativo da retina é uma lesão rara, cujo principal diagnóstico diferencial é o hemangioma capilar da retina. Otumortem natureza reacional. Pode ser idiopático ou secundário a outras doenças como: uveítes, retinose pigmentar, retinopatia da anemia falciforme, cirurgia prévia e retinopatia da prematuridade. Lesões sem exsudação ou baixa visual podem ser observadas. Quando há indicação de tratamento este pode ser feito pela crioterapia, vários tipos de lasers, excisão cirúrgica, radioterapia e injeções intravítrea de antiangiogênicos, isoladamente ou em associação.

Descritores: Retina/patologia; Neoplasias da retina/diagnóstico; Neoplasias da retina/patologia; Neoplasias da retina/terapia

\section{INTRODUCTION}

The histopathological description of what we now know as retinal vasoproliferative tumor (RVPT) was first done by Henkind and Morgan back to 1966, based in findings that they quoted as "Coat's like" appearance in eyes enucleated due to other diseases ${ }^{(1)}$. From that starting point, eventual case reports and small case series describing the clinical aspects of primary and secondary peripheral vascular retinal tumors posing a diagnostic dilemma with uveal melanoma and retinal capillary hemangioma started to came out ${ }^{(2-6)}$. In 1995, Shields et al. reported 103 cases of peripheral acquired retinal vascular tumor and proposed the term RVPT ${ }^{(7)}$.

Our goal is to review the clinical picture, differential diagnosis, etiology, histopathological aspect and management of RVPT, based on major publications about the topic and on our personal experience with this rare disease at the Federal University of Bahia and Hospital São Rafael, two major regional referral centers for eye tumors in Bahia - Brazil.

\section{CLINICAL PICTURE AND DIFFERENTIAL DIAGNOSIS}

RVPT can be primary (idiopathic) or secondary (associated) to other ocular diseases like retinitis pigmentosa, sickle cell retinopathy, Coat's disease, retinopathy of prematurity, toxoplasmosis, toxocariasis, tuberculosis, other uveitis, ocular trauma, retinalchoroidal coloboma and retinal detachment ${ }^{(1-3,7-13)}$. Primary tumors correspond from 53 to $80 \%$ of the cases in the major reported series ${ }^{(7,9,13)}$.

RVPT affects patients of both genders and all ages, but there is a predominance of women after the $5^{\text {th }}$ decade ${ }^{(7,8,13)}$. Most patients seek medical attention complaining of decrease in visual acuity, although some cases are discovered on routine evaluation ${ }^{(7-13)}$. Floaters, photopsias and metamorphopsia are other common complaints.

RVPT usually presents as a solitary mass in the retinal periphery. The inferior retina is affected in 60 to $90 \%$ of cases and the temporal retina in 42 to $75 \%$ of cases (Figure 1) ${ }^{(7,13)}$. Bilateral lesions or even multiple lesions in the same eye can be seen, specially in secondary RVPTs (Figure $2 \mathrm{~A}$ ). Shields et al. report multiple tumors in $6 \%$ of primary and $41 \%$ of secondary RVPTs ${ }^{(7)}$. We have managed and followed 10 eyes of 8 patients with RVPTs, all tumors were temporal, 8 in the inferior and 2 in the superior retina. Three cases were considered to be secondary: 2 patients with retinitis pigmentosa and bilateral RVPTs; and 1 patient with type 2 neurofibromatosis and a blind painful eye due to neovascular glaucoma after two episodes of blunt trauma.

RVPTs usually exhibit a red to orange color and can present with hard exsudates originating in the tumor, subretinal fluid, subretinal or even vitreous hemorrhage, vitreous cells, cystoid macular edema, epiretinal membrane, subretinal membrane and hypertrophy of retinal pigmented epithelium (RPE) (Figure 3)(7-10,13).

RVPTs may exhibit feeder vessels, although with less dilation and tortuosity than that seen on retinal capillary hemangioma, its major differential diagnosis ${ }^{(7,8,13)}$. Among other lesions that can be confounded with RVPTs are: choroidal amelanotic melanoma - that can be differentiated based on its choroidal location and typical echographic findings of low and decreasing internal reflectivity with choroidal shadowing; peripheral hemorrhagic and exsudative choroidopathy - that usually occurs in older patients; and inflammatory lesions like
Submitted for publication: August 23, 2012

Accepted for publication: March 23, 2013

Study carried out at Universidade Federal da Bahia e Hospital São Rafael, Salvador (BA), Brazil.

${ }_{1}^{1}$ Physician, Faculdade de Medicina da Bahia, Universidade Federal da Bahia, Salvador (BA), Brazil. 2 Physician, Hospital São Rafael, Fundação Monte Tabor, Salvador (BA), Brazil.
Funding: No specific financial support was available for this study.

Disclosure of potential conflicts of interest: E.F.Marback, None; R.L.Guerra, None; O.O.Maia Jr. None; R.L.Marback, None.

Correspondence address: Eduardo Marback. Rua Eduardo José dos Santos, 147 - Sala 808 - Salvador (BA) - 41940-455 - Brazil - E-mail: eduardomarback@uol.com.br 

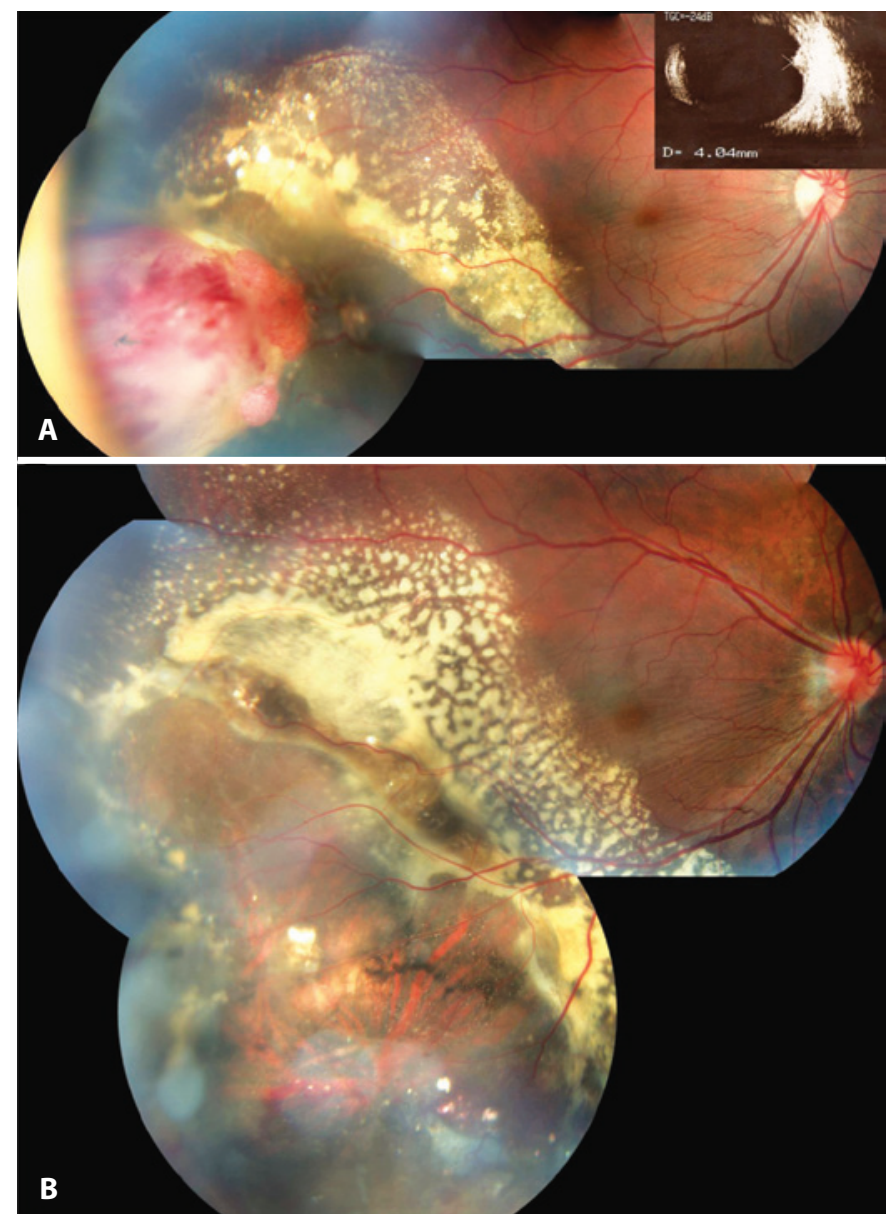

Figure 1. A) Typical tumor location in the inferior temporal periphery with massive exsudation, note in the insert that this was a $4.04 \mathrm{~mm}$ thick RVPT. B) Same case after cryotherapy followed by bevacizumab injection.

uveal tuberculoma and granuloma due to sarcoidosis - lesions that frequently are located in the periphery and frequently exhibit vitreous cells, just like a RVPT, but lack the typical vascular component and usually have a pale aspect ${ }^{(12,14)}$

Complementary tests include echography, fluorescein angiography (FA) and optical coherence tomography (OCT). Echography shows a solid tumor with medium to high internal reflectivity and lacking choroidal shadowing (Figure $2 \mathrm{~B}$ and $\mathrm{C}$ ). Echography is also useful to measure (most of RVPTs are less than $3 \mathrm{~mm}$ high) and follow RVPTs' response to treatment ${ }^{(7,10,13)}$. FA is usually of limited value due to the preferred peripheral location of RVPTs. When feasible RVPTs AF reveals early filling in the arterial phase with increasing hyper fluorescence and late leakage $\mathrm{e}^{(7,10,15)}$. OCT also has a limited role for the same reason as $A F$, but is frequently used to document and follow the secondary retinal findings like edema and membrane formation (Figure 3)

Despite its benign nature, RVPT can cause severe visual loss due to the secondary compromise of the vitreous and retina (epiretinal and subretinal membranes, vitreous hemorrhage, subretinal fluid and exsudation) or, less frequently, neovascular glaucoma the can result in a blind painful eye and may prompt removal of the globe ${ }^{(8)}$

\section{ETIOLOGY AND HISTOPATHOLOGY}

The etiology of RVPT is yet to be completely understood. Although most RVPTs are supposedly of idiopathic nature, the study of lesions
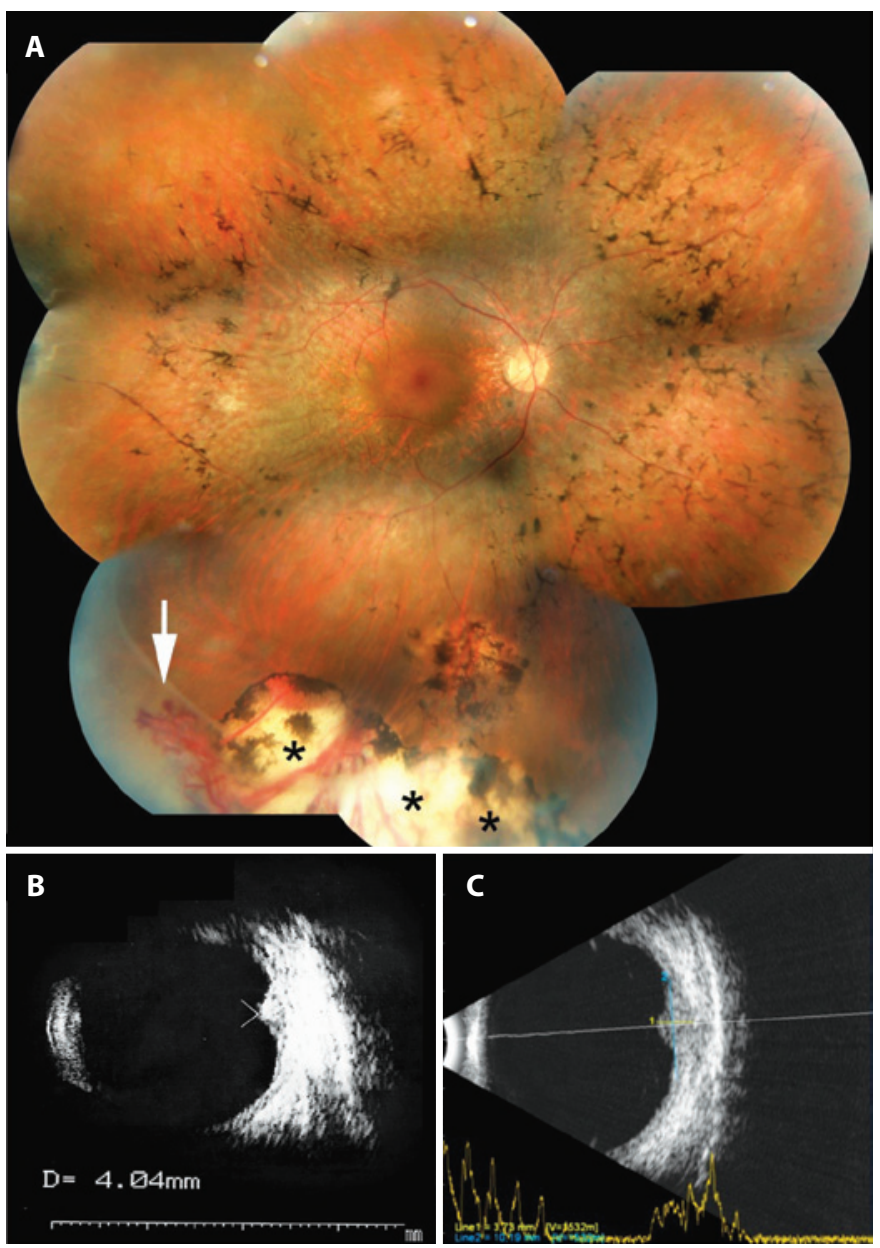

Figure 2. A) Secondary retinal vasoproliferative tumor in association to retinitis pigmentosa (arrow). Asterisks highlight previous cryotherapy scar. B) B scan echography reveals a dome shape lesion with medium high internal reflectivity. C) Note the A scan aspect of medium high reflectivity.

obtained by endoresection or from eyes enucleated due to neovascular glaucoma suggests a reactive, rather than neoplastic nature. The microscopic study reveals a mix of vascular and glial proliferation. The glial component usually exhibits fusiform and rather uniform cells. Vascular component show dilated vessels with mural hyalinization and occasional thrombosis (Figure 4). Proliferative index is low. RPE cells can permeate the tumor mass, exhibiting a variety of phenotypes like macrophages, fibroblasts, cuboidal and pseudoadenomatous with tubuloacinar aspect $t^{(8,16-18)}$. The preferential location of RPE cells around blood vessels or in areas of previous hemorrhage in RVPTs, highlights the reactive nature of those cells ${ }^{(18)}$

The reactive nature of VPRTs is questioned to be a variant of proliferative retinopathy ${ }^{(18)}$. Hiscott and Mudhar, studied 6 enucleated eyes harboring RVPT. They found epiretinal and subretinal membranes containing RPE cells in association with RVPTs in all eyes ${ }^{(18)}$. While Shankar et al. highlighted the vascular content of a surgical excised epiretinal membrane associated to RVPT, calling attention to the resemblance to epiretinal membranes from diabetic patients and questioning the role of RVPTs as a source of vasoactive citokyns ${ }^{(19)}$.

\section{TREATMENT AND PROGNOSIS}

The ideal treatment scheme for RVPTs is yet to be determined. A number of different treatment approaches have been described with variable success rates, usually on case reports or small case series $(7,9,10)$. 

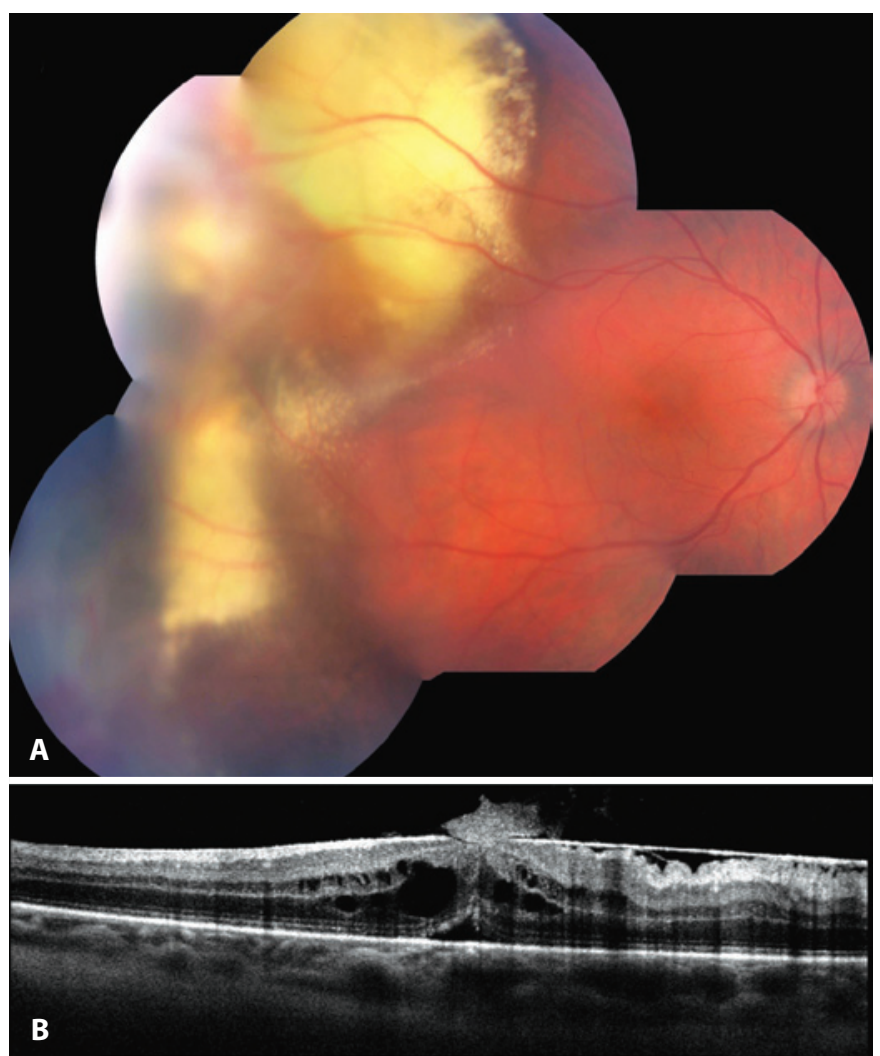

Figure 3. A) Tumor in the temporal superior periphery with massive exsudation. B) Optic coherence tomography of the same case showing cystoid macular edema and epiretinal membrane.

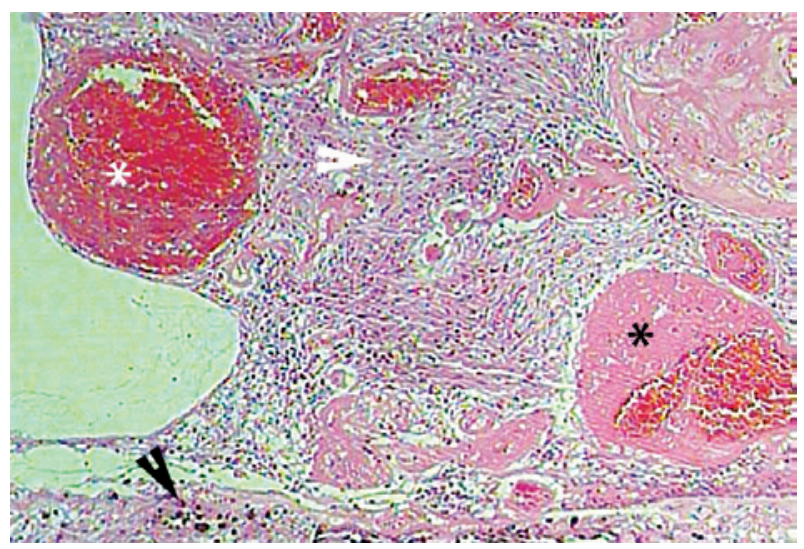

Figure 4. Microscopic aspect of a retinal vasoproliferative tumor in a blind painful eye enucleated with neovascular glaucoma. The vascular component is composed of dilated vessels (white asterisk) some with partial thrombosis of the lumen (black asterisk). White arrowhead points to an area of gliosis. Black arrowhead points to an area of retinal pigment epithelial proliferation at tumor's base.

In the largest published series on RVPTs, Shields et al. used the presence of subretinal fluid, macular edema, epiretinal membrane close to the macula or exsudates close to the macula as criteria to treat or observe RVPTs' patients ${ }^{(7)}$. Based on these criteria $51 \%$ of the eyes needed treatment in their series ${ }^{(7)}$.

Various treatment modalities are available including cryotherapy, laser photocoagulation, photodynamic therapy (PDT), brachytherapy, surgical resection, intravitreous injections and immunomodu- lators. All of them can be used alone or in combination, as we will discuss in the following sections.

\section{Cryotherapy}

It seems to be the most frequently employed treatment modality for RVPTs ${ }^{(7,9)}$. As RVPTS are usually located in the periphery, cryotherapy can be applied in a transconjunctival way, under observation through binocular indirect ophthalmoscopy. The treatment goal is to freeze all tumor, allowing slow thawing and repeating the whole process 2 or 3 times. More than one cryotherapy section can be necessary to achieve complete tumor involution specially, in thick tumors. Figure 1 shows a large RVPT measuring $4.04 \mathrm{~mm}$ thick that was successfully treated by cryotherapy followed by one anti VEGF injection for macular edema after the tumor has regressed. A similar approach was successfully employed by Rodrigues et al. who treated a $2.25 \mathrm{~mm}$ RVPT with cryotherapy, associated to triamcinolone intravitreous injection $^{(12)}$.

Cryotherapy can cause some adverse effects like the persistence of macular edema and the occurrence of retinal detachment arising in a retinal tear adjacent to the scared area.

\section{LASER PHOTOCOAGULATION}

Although its use has been reported in RVPTs, it has a limited role. Probably laser photocoagulation should be reserved for small tumors and, most often, as a complement to other treatment modalities, since it is incapable to destruct thick tumors ${ }^{(7)}$

\section{Photodynamic therapy (PDT)}

PDT has been reported as an effective treatment in retinal and choroidal vascular tumors ${ }^{(20-22)}$. There are a few reports of its successful use in RVPT even for larger tumors, like the ones reported by Blasi et al., with a thickness varying from 2.03 to $4.45 \mathrm{~mm}^{(23-25)}$. Its major limitation is the technical difficulties to reach the typical peripheral location of RVPTs.

\section{BRACHYTHERAPY}

Its major indication in RVPTs is for large lesions (more than $2.5 \mathrm{~mm}$ thick) and lesions associated to retinal detachment. In these clinical situations, cryotherapy is prone to wide tissue destruction, intense inflammatory reaction, vitreous hemorrhage and an increase in subretinal fluid. There are reports of well successful brachytherapy for RVPTs using either Ruthenium ${ }^{106}$ or lode ${ }^{125}$, reaching total tumor remission in 88 and $97 \%$ of the cases respectively $(7,13,26)$. However, when there is associated neovascular glaucoma, brachytherapy failed to achieve disease control ${ }^{(26)}$. It is also important to remember the risk of developing some adverse effects of eye irradiation: dry eyes, cataracts, actinic optic neuropathy, actinic retinopathy and neovascular glaucoma.

\section{Surgical Resection}

It is seldom indicated. There are reports of surgical resection for RVPTS that failed to respond to cryotherapy in association to intravitreous injections of antiangiogenics or as a primary treatment in an eye harboring multiple RVPTs and vitreous hemorrhage ${ }^{(27,28)}$. The surgery can be performed through pars plana vitrectomy or by a transcleral route ${ }^{(15,27,28)}$. Cataract is a common complication after vitrectomy in phakic eyes, specially when silicone oil or gas is used to seal the retinotomies necessary to perform tumor's endoresection.

\section{INTRAVITREOUS INJECTIONS}

There are a few reports of antiangiogenic intravitreous injections for RVPTs, like bevacizumab, ranicizumab and triamcinolone ${ }^{(9,12,29)}$ Although the exact effect of these substances on RVPTs is lacking, it seems reasonable to consider their use in association to or after other 
destructive modalities (like cryotherapy) when there is visual acuity decrease due to macular edema.

\section{IMMUNOMODULATORS}

Japiassú et al. reported an isolated case of bilateral RVPTs that showed regression after systemic treatment with infliximab (antibody anti tumor necrosis factor) for associated mixed collagen disea$\mathrm{se}^{(30)}$. In spite of being an isolated report, it is worth of note when we consider the known association of RVPTs with inflammatory ocular processes.

\section{FINAL COMMENTS}

RVPTs is a rare disease that harbors the potential to result in variable visual acuity decrease or even in complications that cause eye loss. Its exact etiology is not known, although reactive mechanisms are, at least in part, clearly implicated. The ideal treatment is yet to be established, since most of what we known is based on isolated case reports or small case series and a major trial comparing the multiple treatment options available is lacking.

From our personal perspective, faced to a new RVPT case the first point to be addressed is the decision to treat or observe. It seems reasonable that patients with good visual acuity, small and stable tumor, no subretinal fluid (or very limited and non progressive) and lacking exsudation can be securely observed on a 3 to 4 months basis. These patients should be oriented to frequently perform self visual acuity test with immediate return if any visual acuity drop or initiation of other symptoms like photopsias or floaters are noted. For symptomatic patients, and even for patients with good vision but exhibiting signs of impending visual acuity risk (like growing tumors with progressive subretinal fluid or exsudates) we advocate immediate treatment. After the decision to treat is taken, one should decide which treatment modality to use. Some authors recommend that tumors thicker than $2.5 \mathrm{~mm}$ should be treated with brachytherapy as an initial approach ${ }^{(7,8,13,26)}$. Nevertheless, brachytherapy is an expensive treatment that is not easy available in most centers. On the other way, successful treatment of thicker RVPT with multiple sessions of cryotherapy, PDT, photocoagulation or the association of cryotherapy with intravitreous injectons of antiangiogenic for the secondary retinal changes were reported $(7,8,25,29,31)$. Such approaches are probably much more commonly employed in the treatment of RVPTs than brachytherapy worldwide ${ }^{(0,31)}$. From our personal perspective, treatment decision should be based on specific tumors characteristics, but also on local availability. For instance, brachytherapy can be considered an indication in thicker tumors, but it should not be considered as the only possible treatment option specially when considered its costs and the fact that it is not available in most referral centers and that other modalities have been successfully employed, even for thicker tumors ${ }^{(31)}$. Probably a tumor located on a PDT amenable position, in a center where PDT is available, will be suitable for PDT treatment, whereas successive gentle cryotherapy sections can be successfully employed in thicker tumors specially if combined to intravitreous injections of triamcinolone or anti VEGF agents (Figure 1) $)^{(9,12,31)}$. It is also important to note that immediately after treatment and for at least a few weeks after, it is common to find an increase in tumor dimensions that is probably caused by intratumoral inflammation or hemorrhage. So the decision to give more treatment or to change the treatment modality should not be done in a precipitated fashion.

\section{REFERENCES}

1. Henkind P, Morgan G. Peripheral retinal angioma with exudative retinopathy in adults (Coat's lesion). Br J Ophthalmol. 1966;50(1):2-11.
2. Galinos SO, Smith TR, Brockhurst RJ. Angioma-like lesion in hemoglobin sickle cell disease. Ann Ophthalmol. 1979;11(10):1549-52.

3. Barr CC, Rice TA, Michels RG. Angioma-like mass in a patient with retrolental fibroplasia. Am J Ophthalmol. 1980;89(5):647-50.

4. Baines PS, Hiscott PS, McLeod D. Posterior non-vascularized proliferative extraretinopathy and peripheral nodular retinal telangiectasis. Trans Ophthalmol Soc U K. 1982; 102(Pt 4):487-91.

5. Shields JA, Decker WL, Sanborn GE, Augsburger JJ, Goldberg RE. Presumed acquired retinal hemangiomas. Ophthalmology. 1983;90(11):1292-300.

6. Laqua $\mathrm{H}$, Wessing $\mathrm{A}$. Peripheral retinal telangiectasis in adults simulating a vascular tumor or melanoma. Ophthalmology. 1983;90(11):1284-91.

7. Shields CL, Shields JA, Barrett J, De Potter P. Vasoproliferative tumors of the ocular fundus. Classification and clinical manifestations in 103 patients. Arch Ophthalmol. 1995; 113(5):615-23.

8. Heimann H, Bornfeld N, Vij O, Coupland SE, Bechrakis NE, Kellner U, et al. Vasoproliferative tumours of the retina. Br J Ophthalmol. 2000;84(10):1162-9.

9. Makdoumi K, Crafoord S. Vasoproliferative retinal tumours in a Swedish population. Acta Ophthalmol. 2011;89(1):91-4.

10. Rennie IG. Retinal vasoproliferative tumors. Eye (Lond). 2010;24(3):468-71.

11. Mori K, Ohta K, Murata T. Vasoproliferative tumors of the retina secondary to ocular toxocariasis. Mori K, Ohta K, Murata T. Can J Ophthalmol. 2007:42(5):758-9.

12. Rodrigues LD, Serracarbassa LL, Rosa H, Nakashima Y, Serracarbassa PD. Tumor vasoproliferativo associado à tuberculose ocular presumida: relato de caso. Arq Bras Oftalmol. 2007;70(3):527-31.

13. Anastassiou G, Bornfeld N, Schueler AO, Schilling H, Weber S, Fluehs D, et al. Ruthenium-106 plaque brachytherapy for symptomatic vasoproliferative tumours of the retina. Br J Ophthalmol. 2006;90(4):447-50. Comment in Br J Ophthalmol. 2006; 90(4):399-400.

14. Marback EF, de Souza Mendes E Jr, Chagas Oliveira RD, Parikh JG, Rao NA. Isolated uveal tuberculoma masquerading as an intraocular tumor in an immunocompetent patient-a clinical-pathologic study with diagnosis by PCR. J Ophthalmic Inflamm Infect. 2011;1(2):81-4

15. Maia Júnior OO, Morita C, Angotti Neto H, Bonanomi MT, Takahashi WY. Tumor vasoproliferativo primário da retina associado a edema macular cistóide: relato de caso. Arq Bras Oftalmol. 2005;68(6):845-9.

16. Irvine F, O'Donnell N, Kemp E, Lee WR. Retinal vasoproliferative tumors: surgical management and histological findings. Arch Ophthalmol. 2000;118(4):563-9. Comment in Arch Ophthalmol. 2001;119(1):145-6.

17. Smeets MH, Mooy CM, Baarsma GS, Mertens DE, Van Meurs JC. Histopathology of a vasoproliferative tumor of the ocular fundus. Retina. 1998;18(5):470-2.

18. Hiscott $P$, Mudhar $H$. Is vasoproliferative tumour (reactive retinal glioangiosis) part of the spectrum of proliferative vitreoretinopathy? Eye (Lond). 2009;23(9):1851-8.

19. Shankar P, Bradshaw SE, Ang A, Rennie IG, Snead DR, Snead MP. Vascularised epiretinal membrane associated with vasoproliferative tumour. Eye (Lond). 2007;21(7):1003-4.

20. Rodriguez-Coleman H, Spaide RF, Yannuzzi LA. Treatment of angiomatous lesions of the retina with photodynamic therapy. Retina. 2002;22(2):228-32.

21. Boixadera A, García-Arumí J, Martínez-Castillo V, Encinas JL, Elizalde J, Blanco-Mateos $\mathrm{G}$, et al. Prospective clinical trial evaluating the efficacy of photodynamic therapy for symptomatic circumscribed choroidal hemangioma. Ophthalmology. 2009;116(1): 100-5.e1. Erratum in Ophthalmology. 2009;116(5):822. Arumí, José García [corrected to García-Arumí, José].

22. Bains HS, Cirino AC, Ticho BH, Jampol LM. Photodynamic therapy using verteporfin for a diffuse choroidal hemangioma in Sturge-Weber syndrome. Retina. 2004;24(1): $152-5$

23. Saldanha MJ, Edrich C. Treatment of vasoproliferative tumors with photodynamic therapy. Ophthalmic Surg Lasers Imaging. 2008;39(2):143-5.

24. Osman SA, Aylin Y, Arikan G, Celikel H. Photodynamic treatment of a secondary vasoproliferative tumour associated with sector retinitis pigmentosa and Usher syndrome type I. Clin Experiment Ophthalmol. 2007;35(2):191-3.

25. Blasi MA, Scupola A, Tiberti AC, Sasso P, Balestrazzi E. Photodynamic therapy for vasoproliferative retinal tumors. Retina. 2006;26(4):404-9.

26. Cohen VM, Shields CL, Demirci H, Shields JA. lodine I 125 plaque radiotherapy for vasoproliferative tumors of the retina in 30 eyes. Arch Ophthalmol. 2008;126(9):1245-51.

27. Yeh S, Wilson DJ. Pars plana vitrectomy and endoresection of a retinal vasoproliferative tumor. Arch Ophthalmol. 2010;128(9):1196-9.

28. Gibran SK. Trans-vitreal endoresection for vasoproliferative retinal tumours. Clin Experiment Ophthalmol. 2008;36(8):712-6.

29. Kenawy N, Groenwald C, Damato B. Treatment of a vasoproliferative tumour with intravitreal bevacizumab (Avastin). Eye (Lond). 2007;21(6):893-4

30. Japiassú RM, Brasil OF, Cunha AL, de Souza EC. Regression of vasoproliferative tumor with systemic infliximab. Ophthalmic Surg Lasers Imaging. 2008;39(4):348-9.

31. Damato B. Vasoproliferative retinal tumour. Br J Ophthalmol. 2006;90(4):399-400. Comment on Br J Ophthalmol. 2006;90(4):447-50. 